\title{
Review: some non-surgical interventions improve symptoms in carpal tunnel syndrome
}

\author{
O' Connor D, Marshall S, Massy-Westropp N.Non-surgical treatment (other than steroid injection) for carpal tunnel \\ syndrome. Cochrane Database Syst Rev 2003;(2):CD003219 (latest version 28 Oct 2002).

\section{QUESTION: In patients with carpal tunnel syndrome (CTS), what is the effectiveness of non-surgical treatment (other than steroid injection) compared with no treatment, placebo, or another non-surgical treament for improving clinical outcome?}

\section{Data sources}

Studies were identified by searching 7 databases and reviewing the reference lists of identified trials.

\section{Study selection}

Published and unpublished studies were selected if they were randomised controlled trials comparing a nonsurgical treatment (other than steroid injections) with no treatment, placebo, or another non-surgical treatment in patients with CTS. Studies of patients with previous surgery for CTS were excluded.

\section{Data extraction}

Data were extracted by 2 independent reviewers on patients, interventions, outcome measures, and results. Study quality was assessed using a descriptive approach according to the Cochrane Reviewers' Handbook. Main outcome was improvement in clinical symptoms (eg, pain and paraesthesiae) $\geq 3$ months after the end of treatment.

\section{Main results}

21 trials met the selection criteria. Interventions evaluated were splinting ( 3 trials); ultrasound (3 trials); ergonomic keyboards (2 trials); oral medications or vitamins (6 trials); and 1 trial each of exercise, yoga, mobilisation, magnet therapy, chiropractic care, laser acupuncture, and insulin injection. Duration of treatment ranged from 45 minutes to 6 months. 10 of the trials had a high bias rating; 8 had a moderate rating. Only 3 trials assessed the main outcome measure. Improvement in $\geq 1$ outcome measure occurred with 9 of the 12 interventions (see table on website). No difference was seen with magnet therapy, exercise, or laser acupuncture, and chiropractic care led to an increase in physical distress (see table on website).

\section{Conclusion}

In patients with carpal tunnel syndrome, most nonsurgical treatments do not seem to improve short term clinical outcome.

1 Marshall S, Tardif G, Ashworth N. Cochrane Database Syst Rev 2003;(1):CD001554

2 Verdugo RJ, Salinas RS, Castillo J, et al. Cochrane Database Syst Rev 2003;(1):CD001552. 